The first success of Born's theory lay in explaining the heat of formation of these compounds. Suppose the sodium and chlorine ions to remain in regular array, but to be widely separated, and then allow the whole structure to collapse uniformly, ending in the sodium chloride crystal. The energy of the electrostatic field between the ions is reduced in the process, just as when the plates of a condenser come together. This energy can be calculated, and a correction due to the work done against the repulsive forces can be worked out. The latter is small because it only comes into play at the very end of the process. Born showed that the calculated loss of energy was in accord with the heat of formation of the crystal.

(To be continued.)

\title{
Determination of Position in High Latitudes, with Particular Reference to Aircraft Observation.
}

\section{By C. J. STEWART, O.B.E.}

$\mathrm{T}^{\mathrm{H}}$ HE determination of position from land or air observations in high latitudes is rendered difficult, apart from conditions of temperature, by the unreliability of the magnetic compass and gyroscopic compass. On aircraft the latter is not yet a practicable instrument. Hence, astronomical methods must be utilised. In the consideration of any method of air navigation to the poles it must first be made clear that, even with assumed perfectly accurate instruments and accurate observations with them, astronomical observations from an aeroplane can give an exact position in two cases only: (1) by the observation of two stars; (2) by choosing the time of flight so as to render possible simultaneous observations of both sun and moon. The first case implies that the flight takes place at the season of perpetual night, and need not therefore be considered. The limitations of the second case are increased by the known inaccuracy of any form of sextant used in the air. Broadly, while sextant observations on the ground may be relied upon to give position within, say, one to three miles, aerial observations can only be relied upon to give position within about ten miles, and it is usually necessary to take the mean of a number of readings to secure this result. The use of automatically stabilised aircraft may render a somewhat more accurate location possible, but the utility of such aircraft under polar conditions can scarcely be regarded as established.

In view of such limitations, reliance has to be placed upon other means of navigation. Radio direction-finding is unlikely at the present stage of development to be of use, since its accuracy at a range of, say, four hundred miles would not, under favourable conditions, give position in line to within twelve miles. Radio signalling is, however, of value for providing exact time signals. The navigator is therefore compelled to rely upon the use of the most accurate instruments for-

(1) indicating direction, and

(2) indicating ground speed in magnitude and direction.

This, of course, is virtually the oldest method of navigating, namely, dead reckoning. ${ }^{x}$ The instrument used for indicating direction must be some form of sun compass or a gyro azimuth. Of these alternatives, where the sun is available, the sun compass is likely to be the more accurate, since an instrument measuring the sun's position, in con- junction with an accurate chronometer, would be simpler and less liable to variation than any form of gyro azimuth at present known. The feasibility of using gyroscopic devices will be referred to later, but since the sun compass formed an essential part of the equipment of both Amundsen and Byrd in their polar expeditions, a description of such an instrument is necessary.

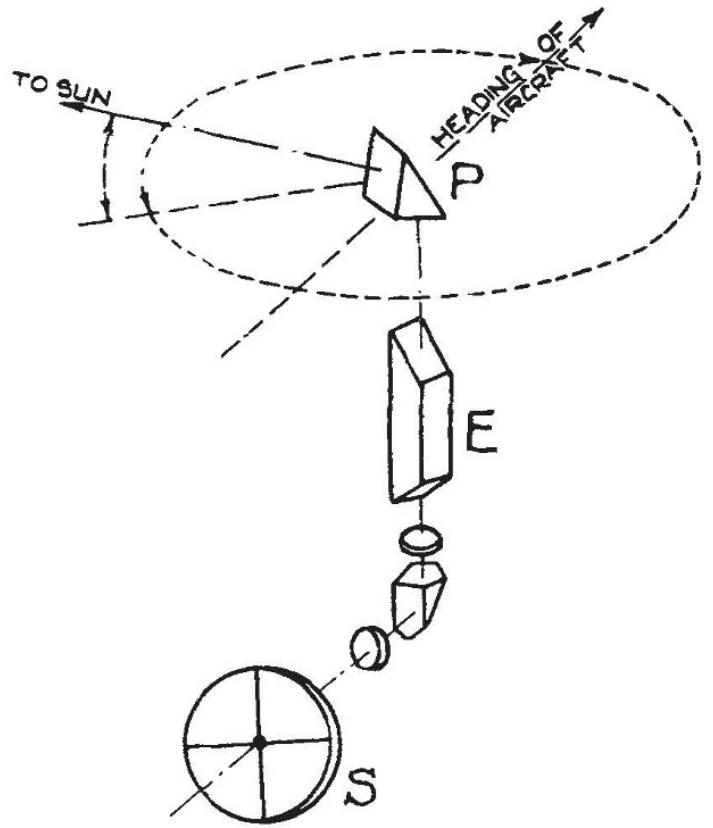

FIG. 1.-Optical arrangement of the Goerz sun compass.

Instruments for measuring ground speed and direction are quite well known ${ }^{2}$ and, in their use under polar conditions of temperature, present no great difficulty.

Since the sun is above the horizon during the exploring season, and since it is always at a low altitude, the sun compass forms a very suitable instrument for determining directions. The Goerz sun compass was constructed specially for the Amundsen expedition in 1925 and, according to reports, gave very satisfactory results. ${ }^{3}$

This instrument comprises an optical arrangement which throws an image of the sun on a screen $S$ (Fig. 1), when the aircraft is on the desired course. The reflecting prism $P$ may be rotated 
about a horizontal axis and set according to the declination of the sun. It may also be rotated about a vertical axis and set according to the time of day and the desired course. When the settings have been made, a clock mechanism keeps the prism in the correct orientation. After reflection, the light passes through the erecting prism $E$, which is rotated at one-half the speed of the prism $P$. The light then passes through a lens system to the screen. A vertical line on the screen serves as a lubber line. The compass must be installed with the horizontal part of the optical axis parallel to the longitudinal axis of the aircraft.

Such an instrument will give, of course, a space direction and not an earth direction. Thus, if it is set to give some definite meridian at any given position of the aeroplane, the track of the latter will not be in the direction of the pole unless the position is chosen to lie on that meridian.

By the use, then, of the sun compass and ground speed indicator (incorporating, of course, a drift indicator) the navigator to the pole must attain his object by careful course plotting based on dead reckoning.

Since the determination of ground speed is a vital matter in such dead reckoning, considerable judgment and care is needed in the method of securing a reading. One method is to time the passage of a ground object past two wires on a sight which is so set as to incorporate the height of the aeroplane above the ground, the method itself being based on similar triangles.

This method is liable to error, of course, where the height of the ground is not known exactly. In such a case, the wind speed is determined by flying the aeroplane on different courses and plotting the track or course made good. From two such readings the wind speed and direction may be determined, and thus from a knowledge of the air speed the ground speed on any given course may be obtained.

As an illustration of the difference between ground and air technique for position-finding in high latitudes, the method used by Peary in his journey to the north pole in 1919 may be compared with the method used by Byrd in his flight to the north pole in 1926. Peary followed closely a meridian from the base camp, using dead reckoning for direction and distance, occasionally using a sight on the sun for correcting his distance. When his dead reckoning calculations indicated that he had reached the pole, a meridian sight on the sun showed him that he had covered a distance which would have taken him exactly to the pole had his direction been correct. This sight by itself, however, did not suffice to locate his position on the earth, but a sight on the sun from the same position eighteen hours later in a direction at right angles to the first observation gave his location as five miles from the pole. Byrd in his flight to the north pole in 1926 flew from a known base in a direction indicated by the sun compass and at a ground speed calculated from drift and airspeed observations. At satisfactory intervals of time, observations of the elevation of the sun were taken, which gave him position lines cutting his plotted course at varying angles, some at suitable angles for checking his latitude and distance, others at angles for checking his longitude, and thus his direction.

It will be at once apparent that such aerial observations taken with instruments which, under the best conditions of usage, are subject to error, are less exact than those taken on the ground from the same position at suitable time intervals.

Byrd and his companions in the south polar flight in November 1929 used the dead reckoning method with two sextant readings of the elevation of the sun. Byrd does not claim any considerable accuracy for these sextant observations. His method, which appears as a fine example of dead reckoning navigation, deserves comment. His navigational equipment, comprising a sun compass, drift and ground speed indicator, and airspeed indicator, were all thoroughly tested at the base before the flight to the pole, and were, of course, used with the greatest skill. Any errors due to the use of this equipment can therefore be regarded as being as small as human effort could make them.

The flight may be divided into three parts-

(a) From the base camp to the trail camp of the geological party close to the mountains;

(b) from the trail camp to the south pole and the return to the supply depot at the foot of the mountains ;

(c) from that depot to the base camp.

The base camp and the trail camp had been located by ground observations, and these positions may be regarded as accurate to within one or two miles. The geographical position of the trail camp had been determined by Dr. Laurence M. Gould, the geologist of the expedition, who had also determined the position of the east portal of the Liv glacier, which was a short distance nearer the pole than the camp.

The parts $(a)$ and $(c)$ of the flight need be discussed only briefly, since the territory had been well explored, both from the air and on the ground, and the navigation of it served mainly as a check upon the accuracy of the instruments. The start was made from the base camp at $3 \mathrm{~h} .30 \mathrm{~m}$. Nov. 29, 1929, Greenwich Civil Time. At $8 \mathrm{~h} .16 \mathrm{~m}$. G.C.T. the plane reached the trail camp, 327 nautical * miles nearer the pole and 361 miles from the south pole. On leaving the trail camp the same course was maintained for 16 miles, when it was changed $30^{\circ}$ to the right towards Liv glacier, where a check was obtained from a predetermined position-the east portal of the glacier. Here, owing to difficulty in obtaining sufficient height, the course was changed and continued for 50 miles up and over the glacier. Reaching the plateau, the course was made along the 171st meridian for the flight south to the pole. The position of the aeroplane relative to Mount Nansen and Mount Ruth Gade checked the dead reckoning position from the trail camp. At $10 \mathrm{~h}$. $20 \mathrm{~m}$. the plane was placed on the 17lst meridian at parallel $86^{\circ} 13^{\prime}$, and the sun compass set along that meridian to the pole 227 miles away.

* All the distances referred to are in nautical miles. 
Here, then, one may pause to consider the accu racy with which this actual position was attained in view of the difficulties experienced in reaching the position and the deviation from the course laid down. Subsequent instrumental observations appear to indicate that no considerable error was introduced by the manœuvre. Heading south, and holding the plane as closely as possible to the 171 st meridian by the aid of the sun compass and the drift and speed indicator, it was estimated that the pole was reached at $13 \mathrm{~h} .11 \mathrm{~m}$. Greenwich Civil Time. In this flight it was noted that at local midnight at that meridian, when the sun was beyond the pole and in line with the meridian, the nose of the plane was pointing directly at the sun and a corresponding indication was given by the sun compass, so indicating that the sun compass was showing the direction of the 171 st meridian. There was no outside check on how closely the aeroplane was holding to this meridian except the landfall made on the return journey. Two rough checks on the dead reckoning determination of the distance flown were made at $12 \mathrm{~h} .38 \mathrm{~m}$. and $13 \mathrm{~h} .6 \mathrm{~m}$., when sextant elevations of the sun were obtained. These gave positions from the pole of 56 and 2 nautical miles respectively. The corresponding dead reckoning positions were 50 and 11 nautical miles. Byrd discounts the accuracy of the sextant observations owing to the errors introduced by the motion of the aeroplane, and experienced aerial navigators will agree with his judgment. These checks, nevertheless, serve a very useful purpose since they were the only independent evidence available, and the distances are of the same order as those given by the dead reckoning calculations.

At $13 \mathrm{~h} .14 \mathrm{~m}$. it was reckoned that the pole had been reached, but deviations of the plane to the right and left of the course for a distance of three miles, and covering a further directional distance

of about five miles, decreased any error in the actual location of the pole so far as the flight was concerned. The aeroplane was headed back over the pole and flown down the 168th meridian at $13 \mathrm{~h}$. $25 \mathrm{~m}$., which should have made the course for the Axel Heiberg glacier. At $15 \mathrm{~h} .30 \mathrm{~m}$. the glacier was sighted.

It will be seen, therefore, that, by the skilled use of the drift and ground speed indicators and the sun compass, the navigation had been sufficiently precise to locate the close vicinity of the pole, the sextant observations serving as the check on the dead reckoning determination given by the speed indicator and compass.

It will be noted that a journey of some seven hundred miles was made in a period of about ten hours. In a land exploration a normal distance in such a time would be about ten miles, during which time observations of the position can be made as necessary, although the difficulty of making these relatively exact determinations is far greater than that of obtaining data in an aircraft.

Although gyroscopic methods of position finding in high latitudes suggest themselves as theoretically feasible, it is not profitable in the present state of the art of using aerial or other gyroscopes to discuss such means for position finding. Not only would such gyroscopes have to be far more exact in functioning than any so far produced for aerial work, but also the conditions of temperature would inevitably introduce such troubles in running that prolonged and arduous research would be necessary to devise the apparatus. The dangers of relying solely upon such means in an aerial polar expedition are so numerous as to render any such scheme impracticable.

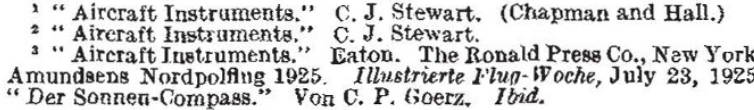

\section{Obituary.}

Prof. F. W. Clarke.

$\mathrm{H}^{\mathrm{R}}$ RANK WIGGLESWORTH CLARKE, born on Mar. 19, 1847, at Boston, Massachusetts, was well known among inorganic chemists, mineralogists, and geologists in Great Britain. For mineralogists and geologists his "Data of Geochemistry" was a handbook full of invaluable information, not in other ways readily accessible, especially at the time of its first publication in 1908 . In addition to his work directly related to geology and mineralogy, he did important work on atomic weights and thermochemical constants. He was chairman of the Inter. national Committee on Atomic Weights in 1900; president of the American Chemical Society in 1901, of the Washington Academy of Arts and Sciences in 1911, and of the Washington Philosophical Society in 1896. He was a foreign member of the Geological Society of London; an honorary member of the Chemical Society, of the Mineralogical Society, and of the Manchester Literary and Philosophical Society; and a corresponding member of the
British Association and of the Geological Society of Edinburgh. He was given the honorary degree of D.Sc. by Victoria University, Manchester, and LL.D. by the University of Aberdeen.

Clarke graduated at Harvard in 1867. His first teaching post was in the Department of Chemistry at Cornell University, Ithaca, New York. in 1869. $\mathrm{He}$ became professor of chemistry in Cincinnati University, Ohio, in 1874. His first paper, in 1868, was "On a New Process of Mineral Analysis". At Cornell he turned his attention to the determination of atomic volumes of solids and liquids as well as to inorganic analytical methods, and during his professorship at Cincinnati he published, in the Smithsonian Miscellaneous Collections, a series of articles on "The Constants of Nature", concluding, in 1883 , with the recalculation of atomic weights, of which a new edition was published in 1898 .

In 1883 Clarke joined the U.S. Geological Survey and became chief chemist, a post which he held until 1925. He was also professor of mineral- 